The Newcastle Upon W/HS Tyne Hospitals NHS Foundation Trust
Synacthen induced pheochromocytoma crisis,

\section{an unusual presentation}

Dr Ali Aldibbiat, Dr Murali Ganguri, Mr Bliss, Dr Andy James

Department of Endocrinology, Royal Victoria Infirmary, Newcastle up on Tyne

\section{Case background}

> 75 male with ankylosing spondylitis with Atlanto-axial joint instability was referred to the endocrine service following an incidental pituitary macroadenoma noted on MRI-C-spine in July2007 measuring $4.2 \times 3.1 \times 3.3 \mathrm{~cm}$ (Figure 1).

$>$ History and examination were significant of loss of libido, reduced secondary sexual characteristics and left quadrantanopia.

$>$ Endocrine studies showed

○ Thyrotoph failure: TSH $1.63 \mathrm{mIU} / \mathrm{L}$, FT4 10 pmol/L, FT3 3.3pmol/L

○ Gonadotroph failure: $\mathrm{LH} 1.7 \mathrm{U} / \mathrm{L}$, FSH 2.6U/L, Testosterone

$3.8 \mathrm{nmol} / \mathrm{L}$, Free Testosterone $65 \mathrm{pmol} / \mathrm{L}$

- Normal lactotroph: Prolactin $319 \mathrm{mIU} / \mathrm{L}$

- Normal HPA axis: normal short Synacthen test

- Normal somatotroph: GH 3mU/L, IGF-1: $14 \mathrm{nmol} / \mathrm{L}$

$>$ MRI-pituitary confirmed an adenoma measuring $4.2 \times 3.1 \times 3.3 \mathrm{~cm}$ (Figure 2).

$>$ He underwent transsphenoidal pituitary surgery followed by external beam radio therapy (EBRT) due to tumour residuum.

$>$ His quadrantanopia resolved completely post-operatively

$>$ He was commenced on Thyroid and testosterone replacement therapies

$>$ Anterior pituitary function was assessed annually afterwards and he remained stable and well until 2011

\section{Case progress}

$>$ During his annual pituitary assessment in February 2011 he developed palpitations and collapsed following Synacthen injection which was given for short Synacthen test (SST). SST showed normal response

$>$ He recovered soon and initial general work up demonstrated no clear cause.

$>$ A repeat SST in September 2011 resulted in palpitations and near collapse. He noted an evolving history of frequent episodes of palpitations and sweating accompanied by headache over the course of the year which raised suspicion of pheochromocytoma.

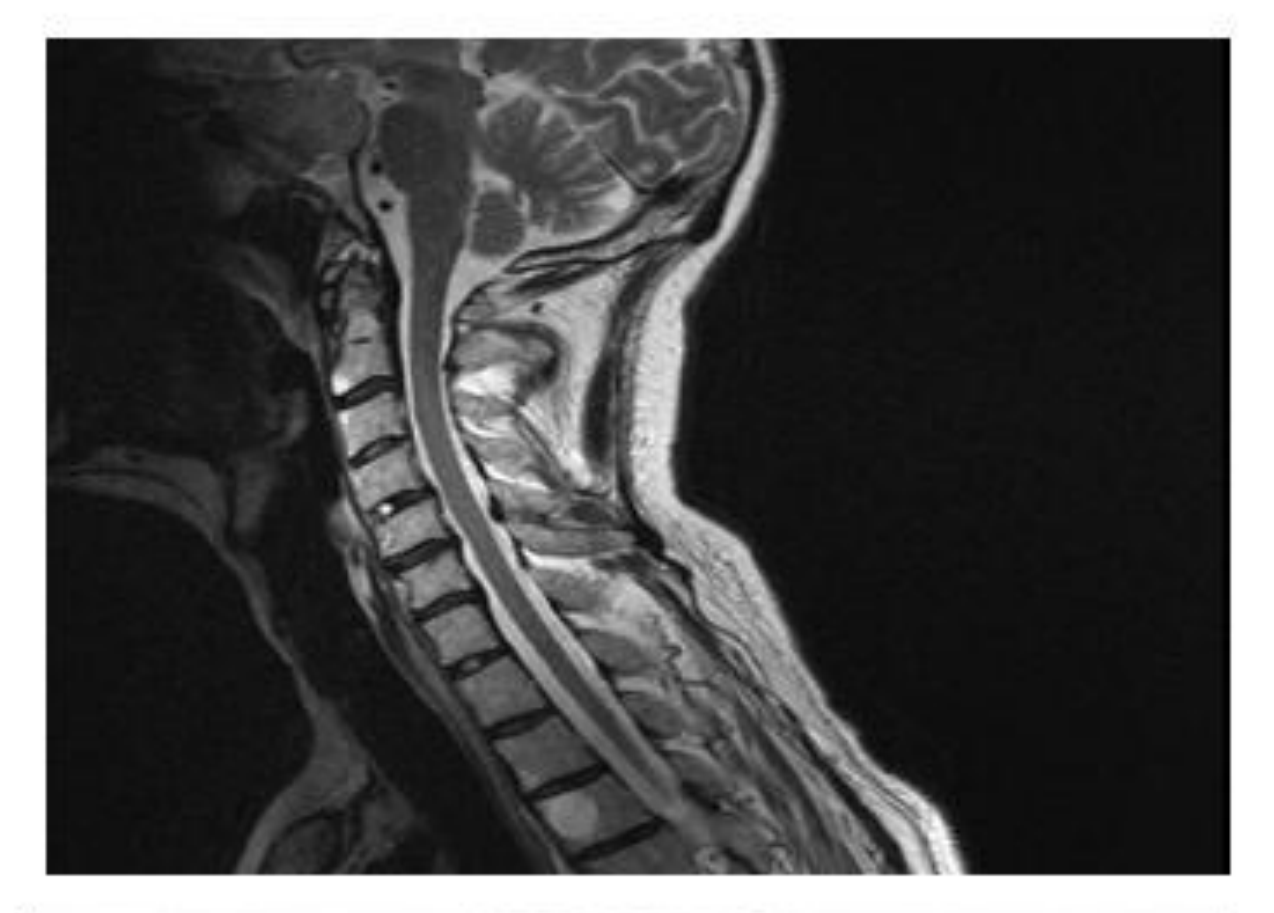

Figure 1. Cervical spine MRI demonstrated incidental Pituitary adenoma.

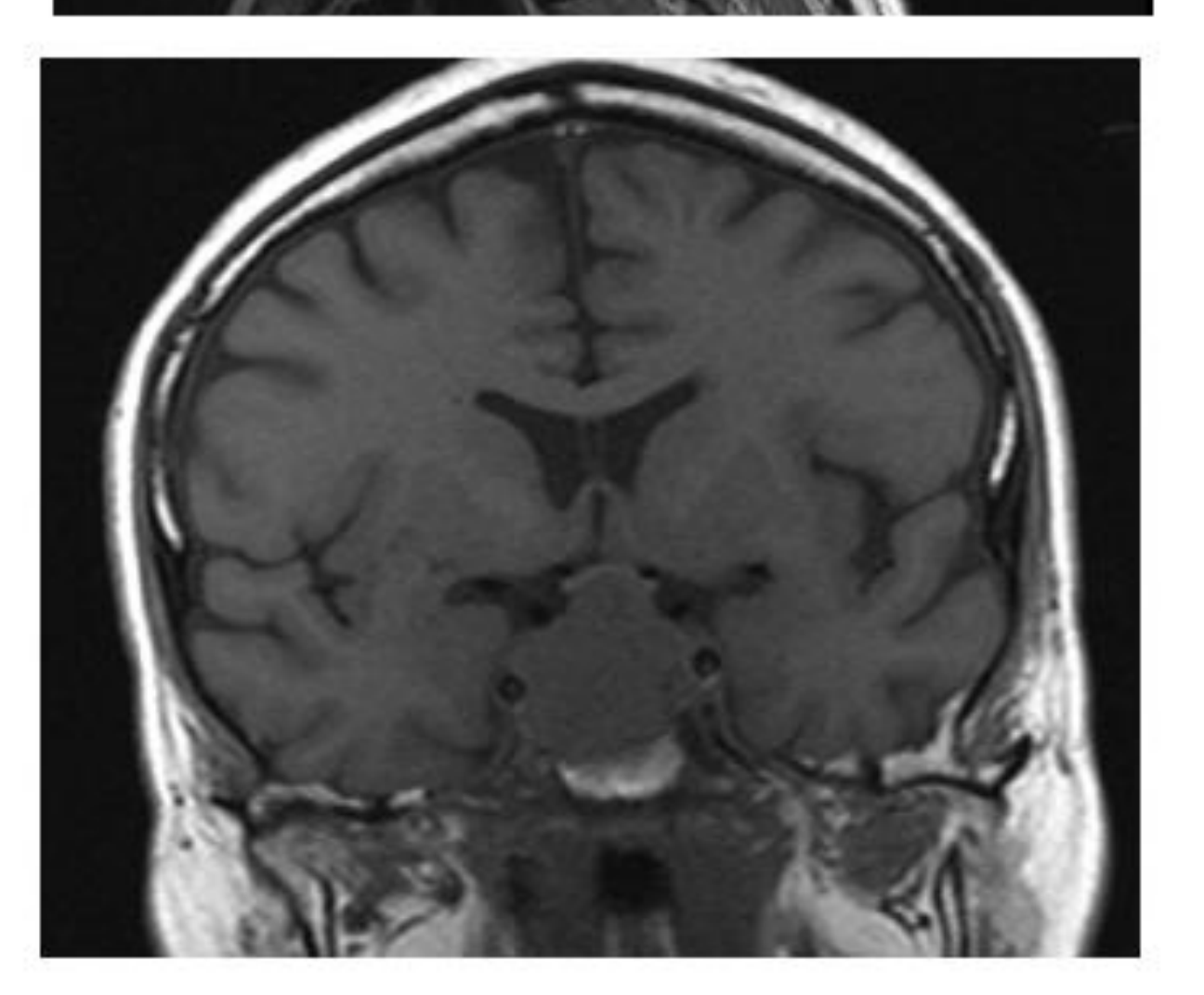

Figure 2. There

MRI-pituitary

demonstrating

pituitary adenoma

\begin{tabular}{|l|l|l|l|l|l|}
\hline Date & $11 / 13$ & $06 / 12$ & $01 / 12$ & $11 / 11$ & Reference \\
\hline $\begin{array}{l}\text { P-Normetanephrines } \\
\text { pmol/L }\end{array}$ & 782 & 321 & 5387 & 3833 & $(12-1180)$ \\
\hline $\begin{array}{l}\text { P-Metanephrines } \\
\text { pmol/L }\end{array}$ & 212 & 162 & 3008 & 1140 & $(80-510)$ \\
\hline $\begin{array}{l}\text { Normetaneph/creat } \\
\text { (pmol/umol) }\end{array}$ & & & 0.76 & & $0.0-0.35$ \\
\hline
\end{tabular}

Table 1. Plasma metanephrines. The rise noted in November 2011 and January 2012 did normalise after phenochromocytoma resection.

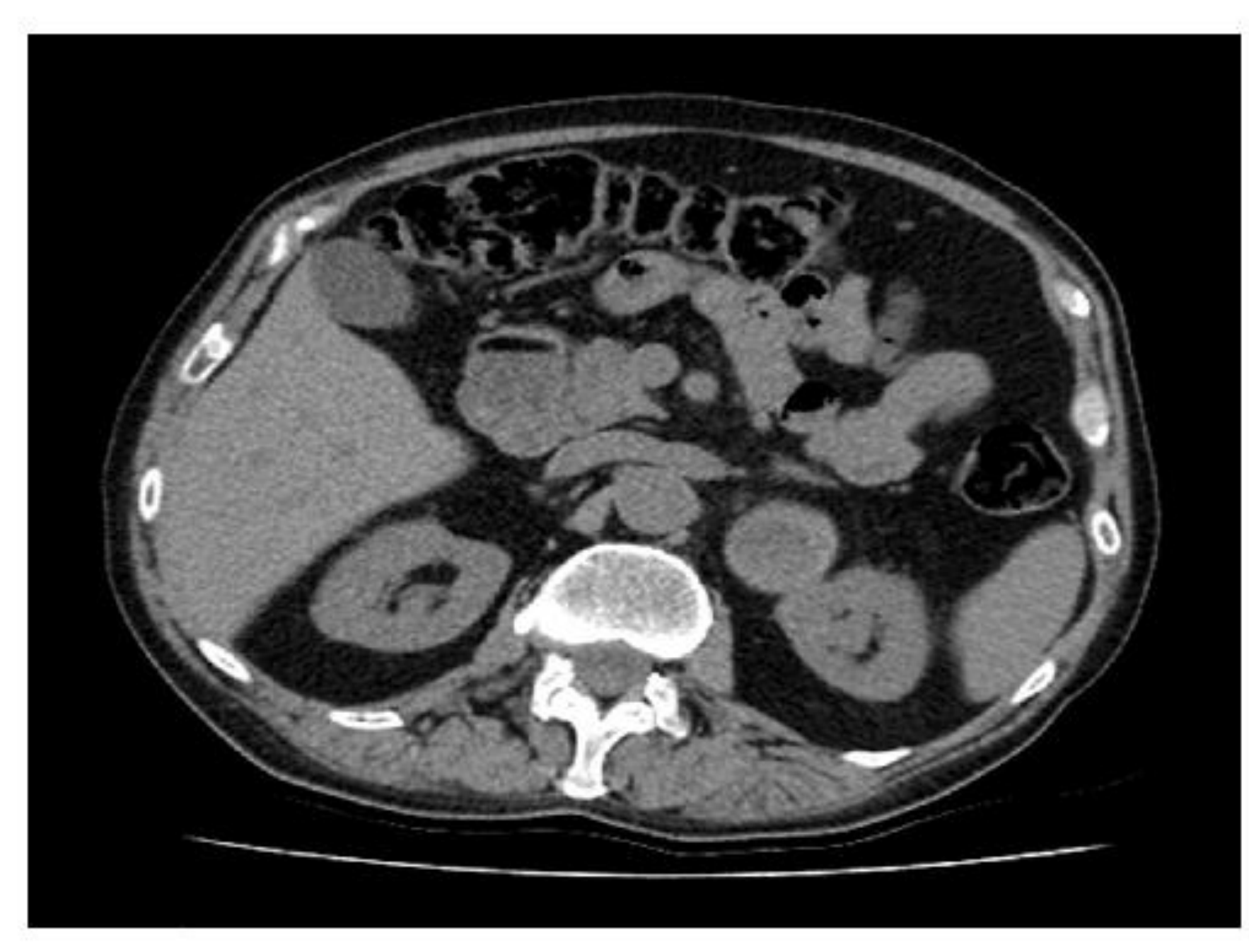

Figure 3. CT-adrenal showing left adrenal adenoma

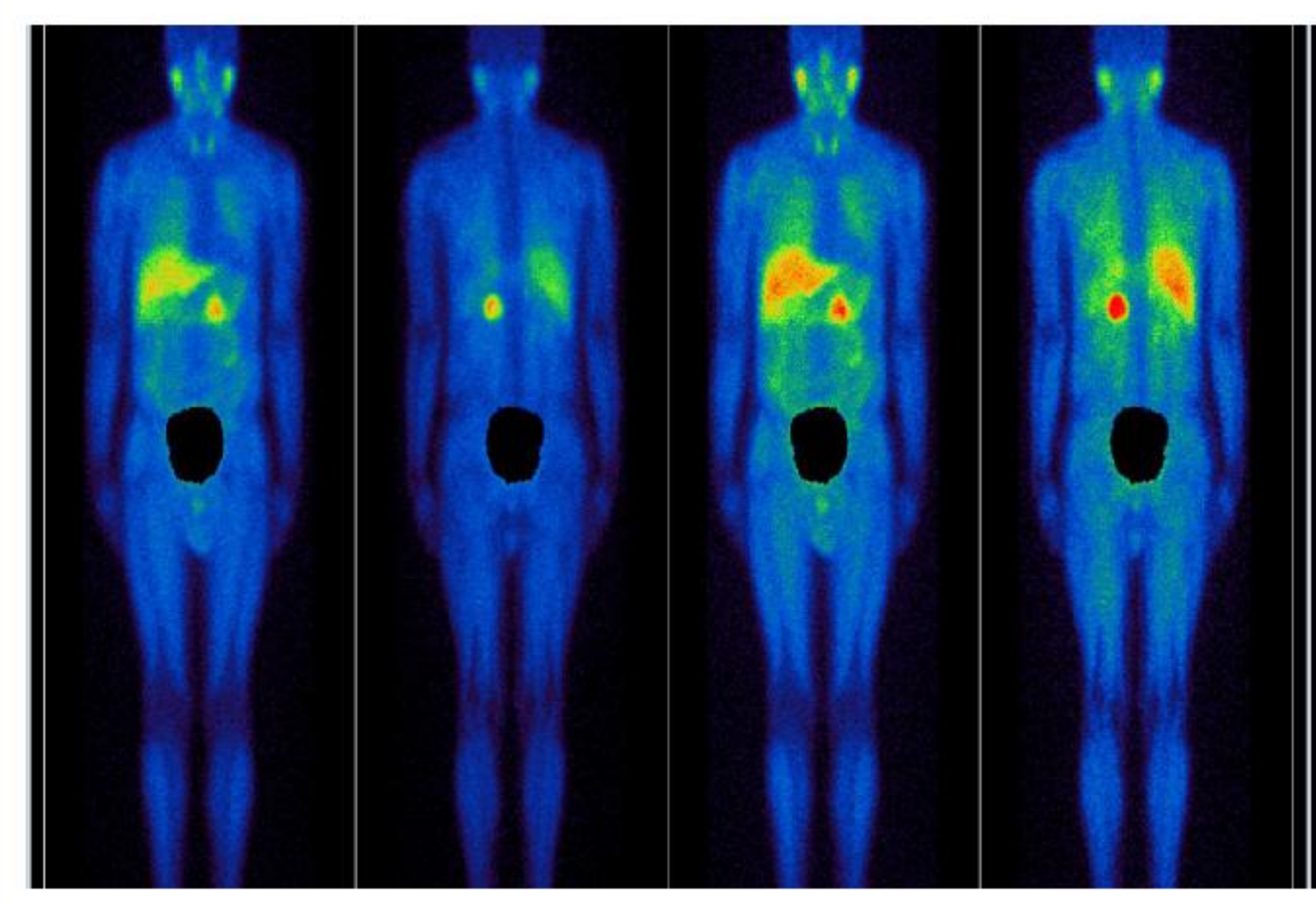

Figure 4. MIBG scan demonstrating left adrenal uptake in concordance with CT-adrenal finding.
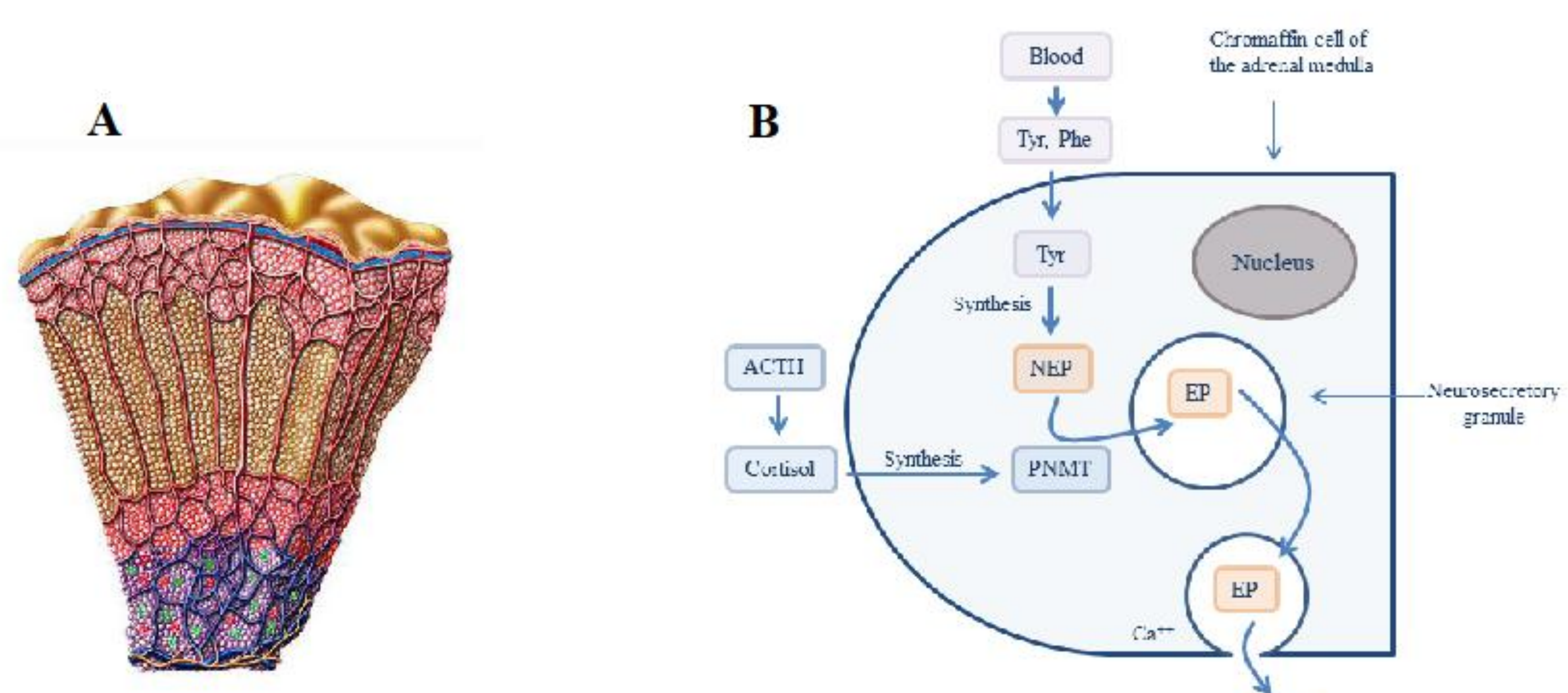

Figure 5. A: anatomy of the adrenal gland demonstrating the blood flow from the cortex through the medulla. B: epinephrine synthesis in the chromaffin cell in the adrenal medulla and the rule of cortisol in inducing PNMT.

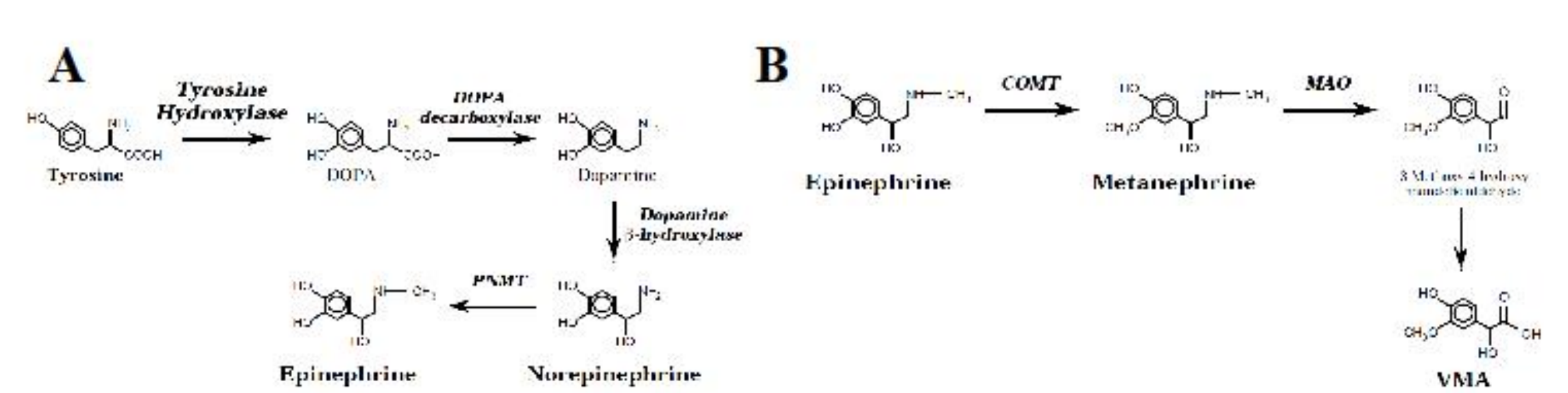

Figure 6. A: biosynthesis of catecholamines. B: inactivation of catecholamines.
Work up and management

> Plasma metanephrines were checked (November 2011) which showed marginal elevation (Table 1). This rose further after 3 month.

$>$ CT-adrenal showed $4.5 \mathrm{~cm} \times 4.3 \mathrm{~cm}$ mass in the left adrenal with an average HU 26 (Figure 3).

> MIBG scan showed increased uptake in the region of the left adrenal gland consistent with a neuroendocrine tumour (Figure 4).

$>$ Alpha-blockade was established and patient underwent left adrenal resection.

Pheochromocytoma was confirmed on Histopathology. Metanephronines normalised post-op (Table 1).

\section{Discussion}

$>$ In this case we are report Synacthen/ACTH induced pheochromocytoma crisis. To our knowledge this has not been reported before. There is evidence from the literature regarding glucocorticoid induced pheochromocytoma crisis when given in high doses (1).

$>$ Our hypothesis is that Synacthen/ACTH stimulation resulted in sudden rise in cortisol release from the adrenal cortex which in turn triggered the pheochromocytoma crisis.

> Upon release from the cortex cortisol flows through the medulla before reaching the blood stream (Figure 5a), activating of phenylethanolamine N-methyltransferase (PNMT) which converts norepinephrine to epinephrine (Figure 5b, 6a). In this case significant release of cortisol results in overt rise in cortisol in the medulla leading to over-induction of PNMT. Moreover, the rise in cortisol concentration in the blood stream results in decrease of the activity of catechol-O-methyl transferase (COMT), an enzyme responsible for catecholamine inactivation (Figure 6b) therefore prolonging action of catecholamine in the periphery and potentiation of beta-receptor mediated catecholamine action in target tissues.

$>$ Haemodynamic instability following synacthen administration is not expected and should trigger suspicion of pheochromocytoma

\section{References}

Rosas et al, European Journal of Endocrinology (2008) 158, 423-429 Fitzgerald, P. A. (2011). Chapter 11. In Gardner, D. G.; Shoback, D Greenspan's Basic \& Clinical Endocrinology (9th ed.). 